\title{
An Empirical Study on Response to Online Customer Reviews and E-Commerce Sales: From the Mobile Information System Perspective
}

\author{
Gang Liu, ${ }^{1}$ Shaoqing Fei, ${ }^{1}$ Zichun Yan, ${ }^{2}$ Chia-Huei Wu $\left(\mathbb{D},{ }^{3}\right.$ and Sang-Bing Tsai $\mathbb{D}^{4}$ \\ ${ }^{1}$ School of Business, Renmin University of China, Beijing 100872, China \\ ${ }^{2}$ School of Economic and Management, Beijing University of Posts and Telecommunications, Beijing 1000876, China \\ ${ }^{3}$ Institute of Service Industries and Management, Minghsin University of Science and Technology, Hsinchu 304, Taiwan \\ ${ }^{4}$ Regional Green Economy Development Research Center, School of Business, WUYI University, Wuyishan 354300, China
}

Correspondence should be addressed to Chia-Huei Wu; chiahuei530@gmail.com and Sang-Bing Tsai; sangbing@hotmail.com

Received 30 March 2020; Revised 1 September 2020; Accepted 16 September 2020; Published 28 September 2020

Academic Editor: Jinglan Zhang

Copyright (c) 2020 Gang Liu et al. This is an open access article distributed under the Creative Commons Attribution License, which permits unrestricted use, distribution, and reproduction in any medium, provided the original work is properly cited.

\begin{abstract}
Response to online customer reviews helps increase sales. Extensive research has been carried out on this topic discussing tactics of response, while few scholars looked at it from the social network perspective. The problem is not how to respond but to whom to respond. Essentially, it is an effective online social network, not a response itself that generates trust and sales. In this paper, our main work is to use basic theoretical tools of social network theory to reveal the nature of the relationship between online response and performance. We use a web crawler to scrape data and get a sample of 3379 sellers from a B2B website. The regression results are consistent with the theoretical derivation and provide strong evidence for our assumptions and hypothesis. Sellers' response to online customer reviews, especially to negative reviews, has a significant positive effect on its sales. Seller's product price and product heterogeneity play moderating roles in the relationship above. Therefore, sellers should actively participate in online social conversations and get embedded in online social networks. Sellers should see pricing and product diversification strategies as important factors in the networking process. E-commerce platform companies should provide the necessary technical support to accelerate the formation of online communities. Producers should cooperate more with sellers and make full use of the customer review information for product improvement and innovation.
\end{abstract}

\section{Introduction}

Benefited from rapidly developing Internet technology, many companies use E-commerce channels, with low cost and high flexibility, to sell their products. The growth of E-commerce depends on the continued development of extensive Internet $\mathrm{B} 2 \mathrm{~B}$ and $\mathrm{B} 2 \mathrm{C}$ platform companies. The product review system designed by these platforms enables customers to know about the sellers' sales and reviews conveniently and even post some reviews on the completed deals. Customers' online reviews, as the reflection of the sellers' credibility and product quality, have considerable effects on the sales [1-3].
Sellers pay a lot of effort to deal with this phenomenon, but perhaps too much. The traditional review mode of simple scoring and text review by customers on the product or service now witnesses some sellers' "fake positive reviews" behavior by illegal technological means [4]. Such behavior distorts the real deal information, sends false signals to customers, and misleads customer decisions [5]. According to a marketing report from Bazaarvoice, $54 \%$ of the customers in 5 countries said that they would not buy products if they suspected that the product has fake reviews (Bazaarvoice Marketing Research, 2020). A survey from Apptentive shows that $55 \%$ of the reviews on the App Store are fake reviews, and $45 \%$ of the reviews on the Google Play 
Store are fake (Apptentive Marketing Research, 2014). Bad money drives out good money, and the perception of online review helpfulness for customers declined significantly. In a word, the deceived customers no longer know whom to trust. Obviously, without trust, there are no sales. Dimension-reduction attack-a concept from science fiction the Three-Body Problem-refers to the attack ability to reduce the three-dimensional space to two-dimensional space so that the original three-dimensional creatures lose their necessary condition of surviving and living. The question is, for those sellers who never create fake reviews, how do they gain customer's trust in an environment where most customers are skeptical of online reviews.

The answer may lie in the establishment of an effective online social network. The whole problem is essentially due to the anonymity of the online environment. Customers do not know sellers or reviewers, so it is naturally hard for them to trust someone. But if they build an effective and stable online social network among customers and sellers, then the trust will naturally arise. Take celebrities on Facebook as an example. They have established a very strong online network with their fans, and fans themselves also constitute a powerful online community [6]. It is difficult to see distrust in this group. Therefore, our research question could also be transformed into how sellers can build effective online social networks, gain the trust of customers, and improve sales performance.

For this question, scholars have already made a certain degree of exploration-they think that a good response or explanation for reviews could help to gain or regain customer trust. Response to customer reviews helps to convey a convincible signal of good product quality [7]. Response to customer reviews enhances the seller's reputation [8]. Their exploration has already reached the idea of the social network-indeed, sellers need to communicate more with buyers. However, the later researchers did not seem to move on in this road but went to another direction. These research studies gradually begin to analyze what kind of response is more effective. They start to care about whether an instant response or a delayed response is better [9], whether an emotional response or a professional response is better [10], and whether an active response or a defensive response is better [11]. There is a famous saying in Chinese that you explain because you want to hide. Putting aside the credibility of this saying, we simply want to know-when customers are already skeptical of online reviews on the Internet, is it important to analyze tactics of explanation? Besides, we think existing studies seem to have overlooked a very important phenomenon, namely, the mobile Internet. How many people shop on mobile phones, and how many people shop on PCs? The original function of the mobile phone is social connection, so we have reason to believe that people will keep the habits and tendencies of social networking when people are shopping online.

Anyways, we decided to give it a try, to apply social network theory on this topic, to head on another direction, to see whether we can find out some valuable treasure of insights, and to guide our business practice. We carried out the data mining on the sellers and products on the B2B website DHgate.com and built the product sales database involving 3,379 sellers from December 2017 to November 2018. Based on these data, we made an empirical analysis on the internal "constructing" mechanism in the perspective of the social network theory, extended the application scope of the social network theory, conceived a route of analysis on response to online reviews by the social network theory, and finally proposed some practical advice to online retailers and E-commerce platforms.

\subsection{Theoretical Basis and Research Hypothesis}

1.1.1. Theoretical Basis. The concept of the social network is derived from sociology and has been discussed a lot deeper in the early sociological literature [12-14]. A widely recognized divination by researchers is that social network refers to a relatively stable system or structure of social relations between social actors. As the social network theory develops, its application scope has been extending from early sociological research to economic and management research. Scholars like Granovetter [15, 16], Burt [17], Bourdieu [18], and Coleman [19] had deeply discussed the issue of concern involved in the social network theory. Relational analysis, network structure, and social capital are the major theoretical categories covered in this theory. Granovetter [15] proposed that economic actions are embedded in social networks, and such network embeddedness generates trust (strong ties). Importantly, trust can reduce opportunism in a trade to cut down transaction costs. Coleman [19] tried to introduce the concept of social capital into economic analysis. He believed that social capital refers to a kind of asset held by an individual, which mainly acts as a social structure resource. The social capital owned by an individual is directly proportional to his/her ability to get resources. Burt [17] analyzed the effect of individual position in a network on the performance that the middle area with fewer ties between two different networks makes a structural hole. Individuals standing in this area could get more heterogeneous information and gain a competitive advantage.

Plenty of researchers in the management science field applied the social network theory into other research fields. They obtained many outcomes, for example, innovation and entrepreneurship management [20], leadership management [21], human resource management [22], knowledge management [23-25], and stakeholder management [26]. The rapid development of the Internet and the emergence of new management phenomena have brought challenges to researchers and practitioners. In this context, some scholars have applied the social network theory to online scenarios to deal with more common practical and theoretical problems, such as online marketing scenario [27] and online entrepreneurship financing scenario $[28,29]$. However, we see very little literature for online sales scenario. With the increasing scale of online sales, many problems and needs have gradually arisen. Buyers need to get real information about the product quality of sellers. Word-of-mouth generated in online social networks has become an essential purchase 
reference for buyers, and online brands and knowledgesharing communities have also rapidly developed. New phenomena such as the fan economy and social media E-commerce reflect the increasingly social nature of online sales situations, and the social connection between sellers and buyers has been much strengthened. In this background, the application of social network theory and its analysis methods can make a more reasonable and convincing explanation of the latest changing realities.

\section{Research Hypothesis}

2.1. Effect of Online Sellers' Response to Online Customer Reviews on Overall Performance. The connotation of connection strength includes four aspects: (1) the frequency of communication, (2) the degree of reciprocity, (3) the degree of emotional involvement, and (4) the degree of intimacy [15]. The response to the buyer's review changed the original one-way communication from the buyer to the seller to twoway communication. With more feedback, the willingness to communicate is enhanced, and the buyer is more likely to have further communication with the seller. The response is usually accompanied by a solution to the problem and some compensation measures, and the seller also gains knowledge of product improvement. The response to the buyer's review is not only a signal of the quality of the product and service but also reflects the positive attitude of the seller to participate in social interaction and increase the degree of buyer's trust [30]. Moreover, because online reviews are public [7], responses to buyer's reviews may also build a positive impression in potential buyer's minds [31]. Responses increase the strength of the bond between the seller and the buyer. The weak ties that existed before are gradually transformed into strong ties, and many new weak ties are created, as shown in Figure 1.

Granovetter [15] also integrates the ideas of structure law of social networks in previous studies, that is, between two strong ties, there must be at least a weak tie. Naturally, buyers are strongly connected with many acquaintances. When acquaintances such as relatives and friends have a demand for such products, they will look for reliable information brought by strong ties. The tacit knowledge brought by strong ties [32] helps sellers to make a better judgment of market information. Although these questions and answers are open and transparent, because of the different definitions of specific symbols and language patterns, the semantics of communication in weak ties and the semantics of communication in strong ties are different [33]. Correspondingly, the perceived information and knowledge are different, and strong ties help to decode additional information in the language. Fund traders may be able to judge the price movement of securities through a conversation with acquaintances. Through lunch with Buffett, a new understanding of the market could be learned. Seller's network embeddedness is enhanced through more active, frequent, and meticulous social network interactions, which helps to earn trust and obtain the tangible and intangible social assistance of the members of buyers in the social network, which leads to an improvement of performance.
As the frequency of communication between sellers and buyers gradually increases, information can be transmitted from one group to another through a weak tie bridge. Groups are composed of plenty of strong ties and a few weak ties. Strong ties usually lead to homophily among group members [34], while different groups hold heterogeneous information. For sellers, they can obtain a large amount of heterogeneous information by occupying the hollow part in the middle of multiple strongly connected network groups, that is, the position of the structural hole [17] (as shown in Figure 2). Structural hole positions help sellers integrate supply and demand information to innovate and improve products to meet market demand better, thereby improving sales performance. Based on the statement above, we propose the following hypothesis.

Hypothesis 1. The online sellers' response to online customer reviews is proportional to sales performance.

\subsection{Effect of Response to Online Customers' Positive or Neg-} ative Reviews on Sales Performance. There are two types of reviews, positive and negative [35]; negative review usually means the problems of a product or service. On E-commerce sales platforms, this review mechanism is more open, standard, and intuitive. Buyers can make purchasing decisions based on the product and service ratings and specific reviews $[36,37]$. Most buyers are more sensitive to losses than gains, and this is also true in online trading environments where information is asymmetric [38-40]. Buyers, therefore, pay more attention to negative reviews than positive reviews, and many empirical studies support this view [41, 42].

When a negative evaluation occurs, potential buyers can choose to view the dialogue between the seller and the buyer, or they can directly ask the buyers who already complete the transaction, which reflects the formation and development of online knowledge sharing and brand communities. The seller's response to the buyer's negative review not only addresses the buyer's problems but also dispels the doubts of other potential buyers. Also, it increases the attention of potential buyers to this product and increases the prominence of sellers [43]. More importantly, the seller's response to negative reviews increases the number of connections with buyers and plays a decisive role in social embedding, thus laying a foundation for the establishment of strong ties, which helps to obtain the social network members' tangible/ intangible trust and help [44], as shown in Figure 3.

From the perspective of social capital, if we regard the buyer's negative reviews are a crisis of the brand, the seller's response is a process of turning crisis into opportunity and solving the problem. Negative reviews may expose quality problems in the product production process. Sellers need to communicate and coordinate with suppliers to ensure that similar quality problems do not recur in the future, and sometimes some adjustment has to be made about cooperation with suppliers, and these processes require social capital (as shown in Figure 4). With the use of social capital, cooperation is strengthened [45], and future cooperation opportunities are revealed. Both parties to the transaction 


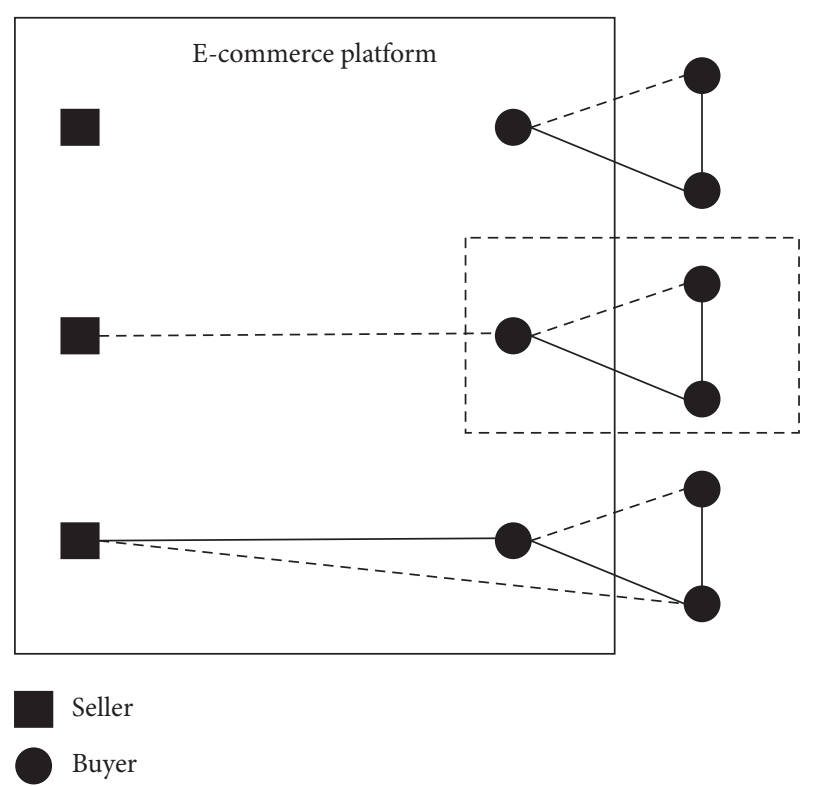

Figure 1: Network formation process among sellers and buyers.

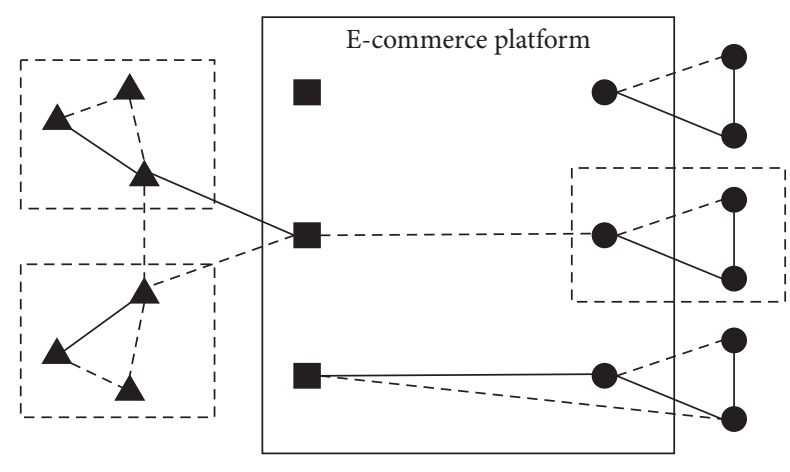

Seller

Buyer

Aroducer

Figure 2: Different network structures among producers, sellers, and buyers.

will know more about others better, which reduces the transaction cost. Therefore, the seller can obtain the channel advantage of the upstream supplier, which is conducive to maintaining an advantageous position in the competition and ultimately improve the sales performance. In general, if sellers can handle the crisis adequately, the amount of social capital will increase, and more competitive advantages will appear. This newly formed social capital will also play a significant buffer role in the subsequent crisis for sellers [46], which supports sellers to survive the crisis [47]. Based on the statement above, we propose the following hypothesis.

Hypothesis 2. Compared with the responses to positive reviews, the raised proportion of the responses to negative reviews is more helpful to improve the sales performance.

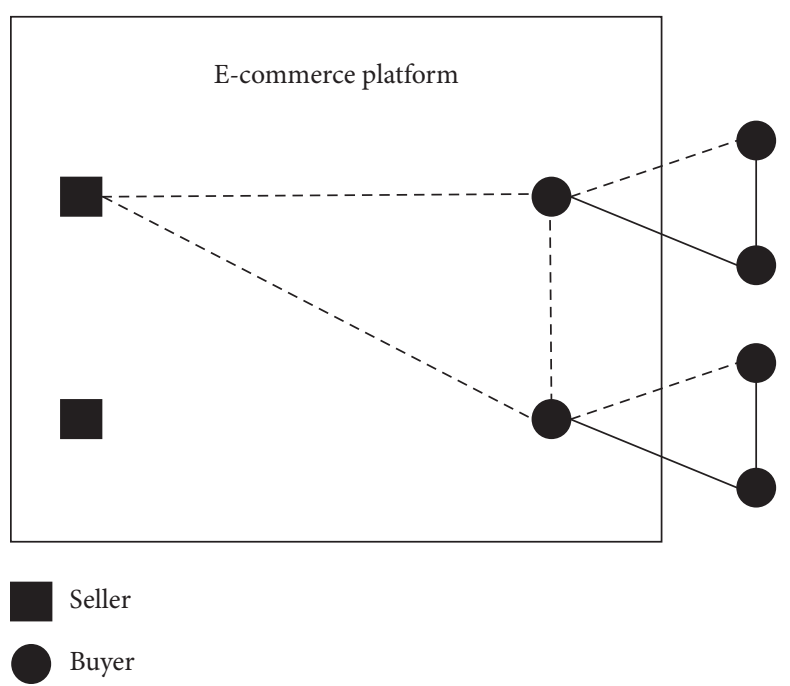

FIGURE 3: Different network structures among sellers and buyers.

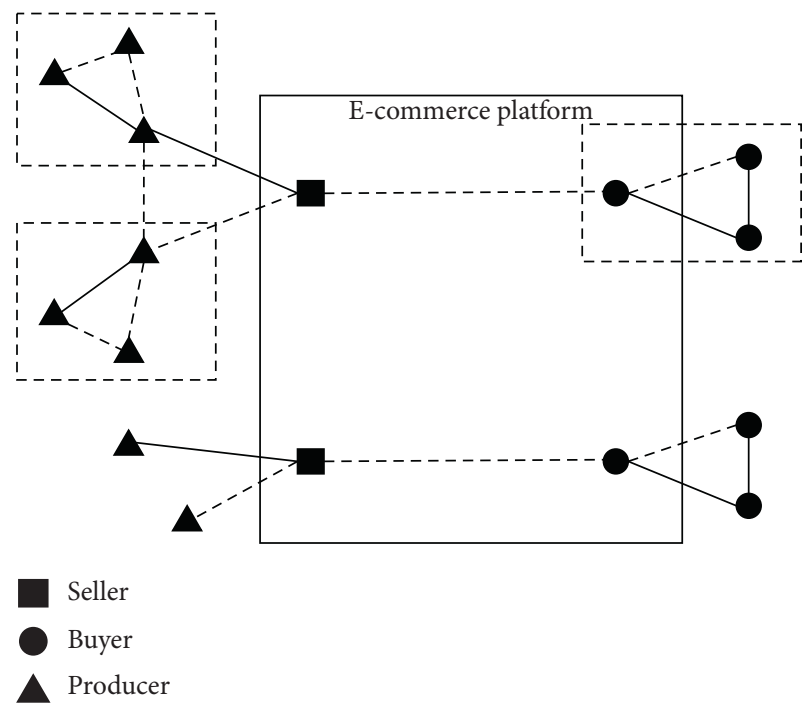

Figure 4: Network structures with different amounts of social capital.

2.3. Moderating Effect of Sellers' Product Prices. Buyers are not sensitive to reviews of all products. Generally, higher product price means higher importance of product expense to customer's work and life [48]. The Internet platform provides the consumers with an abundance of product choices from daily commodities, to luxuries, even to large movables and real estate. The consumers for different products give a different extent of concern for different products on different price levels [49]. On an E-commerce platform with asymmetry information, buyers need to read more reviews to indirectly know the information of product quality, especially for expensive products $[50,51]$. The scope and extent of the influence of reviews are related to price. At the same time, sellers' response to the buyer's review is a response to many groups of potential buyers, so the scope and extent of influence of the response are closely related to the product price. 
In social network theory, network centrality refers to the degree to which an individual is at the center of the network [52]. From the perspective of imperfectly competitive markets, sellers may also influence prices. The stronger the seller's network centrality among suppliers and buyers, the stronger its bargaining power, which leads to increased pricing power for sellers. Conversely, the higher the seller's pricing, the stronger the seller's network centrality. For high centrality actors, they are naturally embedded in social networks. By communicating with them, buyers have increased their embeddedness; therefore, buyers are engaged in discussions about product experiences and product improvements, and sense of involvement is increased [53, 54], which leads to an increased purchasing intention. It is especially true for highly involved products, which often has a strong connection with the price. Generally speaking, for actors at the edge of the network, when they can improve their centrality by connecting with highly centralized individuals, they have a high motivation for investing resources to establish this connection [55], as shown in Figure 5.

From the perspective of social capital, for sellers of higher-priced products, they are more likely to have a higher level of social capital, and the marginal benefit of the social capital of responding to new individuals is higher than that with less social capital. Seller's response behavior could generate network externality. By responding to other buyers, other sellers can also gain demand information, and other buyers can gain product quality information, which enhances the cooperation and communication level of the entire network and increases the social capital. Based on the statement above, we propose the following hypothesis.

Hypothesis 3. The higher the product price is, the stronger the positive effect of the response to online customer reviews is on the sales performance.

\subsection{Moderating Effect of Sellers' Product Heterogeneity.} Product heterogeneity means that sellers' product suppliers are heterogeneous, and target customers are heterogeneous. Heterogeneous customers bring heterogeneous demand information, and heterogeneous suppliers bring heterogeneous supply information. As sellers respond to buyers and communicate with each other more frequently, sellers can establish more weak and strong ties. Through these connections, sellers can build bridges between different heterogeneous network groups and occupy positions of structural holes $[17,56]$, which increase the level of heterogeneity of their information, thereby promoting product innovation [57]. At the same time, it helps sellers to integrate supply and demand information and achieve supply and demand matching.

However, the positions of structural holes are not always conducive to product improvement, and the positions of nonstructural holes are not always bad for product innovation. If an individual is in an empty area between multiple heterogeneous groups, due to the limited attention and resource to maintain the connection, he/she will face a situation of the high network maintenance cost, which may lead to losing the competitive advantage. Strong ties, however, can promote exploitation learning within groups, thereby promoting the process improvement in a particular field [58]. Strong ties will also help the seller better cope with the crisis of quality fluctuations and become a buffer for the seller's brand crisis. In summary, the more heterogeneous a seller's product is, the more the connections needed to be established with heterogeneous buyers. Gradually, more weak connections can be obtained, and more structural hole positions can be occupied, thereby obtaining heterogeneous information. However, the resources and energy of the seller are limited. Too many weak connections mean that there is no time to take care of the original strong ties, which leads to a reduction in embeddedness. The key to maintaining a sustainable competitive advantage is to maintain a reasonable ratio of strong and weak connections (as shown in Figure 6). In this case, the seller's response to the buyer can increase the strength of the connection and increase the proportion of strong ties, thus protecting the competitive advantage already established by the seller.

From the perspective of social capital, the establishment and operation of social capital require resource and time investment [59], but the seller's resources and time are limited. Without the full utilization of the original social capital, the risk of investing in new social capital is too high. It is especially true for sellers who have high product heterogeneity and need significant social capital to coordinate their collaboration. Responses to buyers, rather than continuing to expand product heterogeneity, can ensure the proper functioning of existing social capital. Based on the statement above, we propose the following hypothesis.

Hypothesis 4. The higher the heterogeneity of the products is, the stronger the positive effect of the response to online customer reviews is on the sales performance.

2.5. Source of Data. We choose a sample of 3379 sellers from the B2B platform Dunhuang (DHgate.com). The reasons for selecting a B2B platform are as follows. First, compared with B2C platforms, product specifications, quality standards, and shipping rules are more standard in B2B platforms, which is helpful to exclude endogenous factors of the research. Second, the B2B model has existed for a long time, and the online review and response mechanism of it has been highly developed. Among all kinds of E-commerce platforms, it is more representative and provides relatively rich data for scholars. Third, both sellers and customers in B2B platforms are enterprises in the industry, and their social networks are more stable, which is helpful to exclude the effect of the social network dynamic evolution. We choose Dunhuang specifically because it is the first crossborder B2B website in China. It was established in 2004 and released its transaction data from 2007. By 2018, its annual online dealing volume has exceeded CNY 35 billion. Unlike other B2B websites or B2C websites like Alibaba (Taobao. com) and JingDong (JD.com), Dunhuang allows us to view the information of products and sellers on its website 


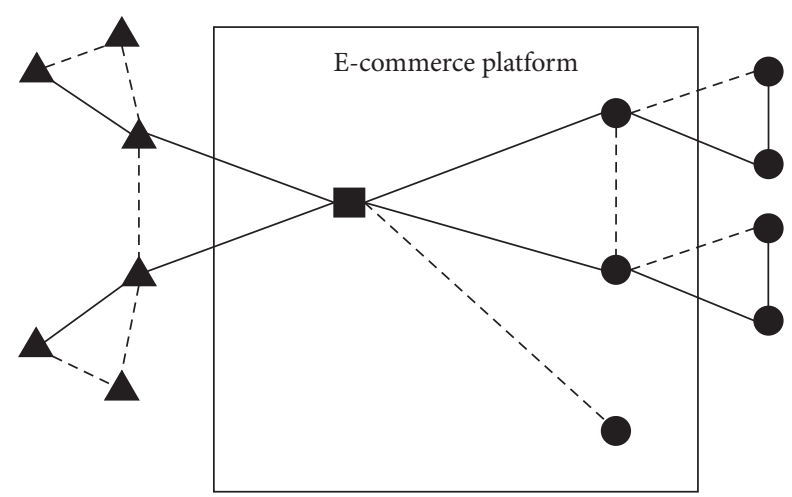

Seller

Buyer

Aroducer

Figure 5: Seller with high network centrality.

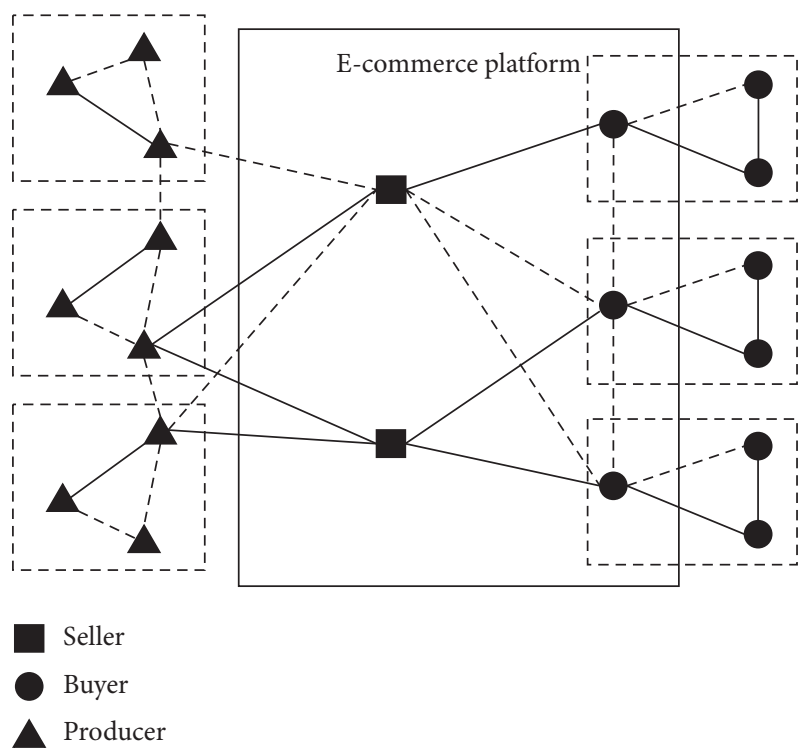

Figure 6: Sellers with different ratios of strong/weak ties.

directly, which provides us with favorable conditions to get the research materials by the data mining method.

The reasons for choosing the time from 2017 to 2018 are as follows. First, before 2017, the functions of review and response were not fully developed. The customer had not yet formed habits of giving online reviews nor had they got used to communicate with other buyers. There lacked a relatively developed online community. Second, we use the data mining method, so it takes time to clean the raw data and build a database. Third, using a one-year dataset instead of a longer-span one can prevent the E-commerce platform from updating its review and response functions and rules and ensure the stability of this study.

The reasons for choosing clothing sellers as the research object are as follows. First, on E-commerce platforms represented by Dunhuang, there are a large number of clothing sellers, which helps to increase sample size and makes the sample more normally distributed, thereby increasing the credibility of the conclusion. Second, clothes are experience goods. Buyers must know the quality of the product after the offline experience. It improves the probability of buyers commenting on the product, which helps to obtain more review data and information in this study.

Like other websites, Dunhuang also allows the customer to score and review the products and sellers to give online responses to all reviews. All the responses and scoring data are displayed on the product home page, and these data can be captured and converted to structured data by the data mining technology. In summary, the information on the clothing and other products sold by the 3379 sellers operating on Dunhuang (DHgate.com) from December 2017 to November 2018 was captured and converted with the data mining technology, delivering a panel database containing 25,798 observed values in the 12 periods (the data are unbalanced panel data because enterprises might enter and withdraw any time during the observation cycle). Our empirical analysis was carried out based on the data above.

\subsection{Design of Variables}

2.6.1. Dependent Variables. According to the research of Deng and Wang [48], the gross sale of the online seller is one of its essential performance indicators. Dunhuang has marked the volume and price of each historical transaction on all product pages. In this paper, we summarize the transaction volume and transaction price of all products for all sellers in a particular month, forming the sales data for the month. As the sales volume data have a large span, we apply logarithm transformation to narrow the scale of the variables. After the logarithm transformation, the property and correlation of the data remain the same.

2.6.2. Explanatory Variables. Based on the research design above, we use the proportion of reviews being responded to total reviews (response ratio) as explanatory variables. Sellers can choose to respond to reviews, and the specific time of all reviews and responses is displayed on the web page. To reflect the sale performance effect of sellers' responses to different types of reviews, we introduced two variables, the rate of response to negative reviews and the rate of response to positive reviews. For the comparison of the regression coefficients of these two variables, we normalized them in the regression model.

2.6.3. Moderating Variables. As mentioned above, in Internet selling conditions, sellers' product price and product heterogeneity play moderating roles on the effect of response to reviews to sales [60-62]. We use logarithmic sale price and the volume of the products sold in the selected month as two moderating variables for product price and product heterogeneity [63-65]. Also, as the product prices have a large span, we apply logarithm transformation to the data. 
TABLE 1: Description list for variables.

\begin{tabular}{|c|c|c|c|c|}
\hline & Mean & Std & Min & Max \\
\hline (1) Sales volume & 8.798 & 7.207 & 1 & 10.117 \\
\hline (2) Ratio of response to negative review & 0.137 & 0.210 & 0 & 0.8 \\
\hline (3) Ratio of response to positive review & 0.069 & 0.114 & 0 & 0.5 \\
\hline (4) Product price & 3.536 & 1.628 & -2.500 & 8.419 \\
\hline (5) Product heterogeneity & 3.728 & 6.535 & 1 & 128 \\
\hline (6) Positive review rate & 0.815 & 0.196 & 0 & 1 \\
\hline (7) Number of reviews & 126.949 & 46.748 & 0 & 240 \\
\hline (8) Trading volume in history & 6.400 & 1.651 & 0 & 11.006 \\
\hline (9) Operation months & 26.511 & 18.378 & 0 & 93 \\
\hline
\end{tabular}

TABLE 2: List of correlation coefficients for variables.

\begin{tabular}{lcccccc}
\hline & 1 & 2 & 3 & 4 & 5 & 6 \\
\hline (1) Sales volume & 1 & & & & & \\
(2) Ratio of response to negative reviews & 0.186 & 1 & & & & \\
(3) Ratio of response to positive reviews & 0.264 & 0.617 & 1 & & & \\
(4) Product price & 0.456 & 0.011 & 0.121 & 1 & & \\
(5) Product heterogeneity & 0.446 & 0.112 & 0.121 & 0.033 & 1 & \\
(6) Positive review rate & 0.175 & 0.110 & 0.085 & 0.153 & 0.318 & 1 \\
(7) Number of reviews & 0.026 & 0.017 & 0.014 & 0.005 & 0.010 & 0.020 \\
(8) Trading volume in history & 0.108 & 0.098 & 0.116 & 0.201 & 0.039 & 0.010 \\
(9) Operation months & 0.004 & -0.024 & -0.031 & 0.045 & 0.073 & 0.411 \\
\hline
\end{tabular}

2.6.4. Control Variables. We also introduce other control variables to control relevant effects and prevent the endogenous problems in the model. We use the rate of positive reviews and the number of reviews as control variables; obviously, these two variables affect sales. We also control the effect of trading volumes in history (logarithmic value) because of the potential bandwagon effect of customers. Operating time since entering the platform may also affect sales, for the longer the time, the more resources and information a seller gets. Furthermore, region, season, and industry dummy variables are all controlled in the model. The data statistics of the variables are shown in Table 1.

\section{Empirical Results}

First, we check the correlation coefficients for the variables with STATA software and give the results in Table 2. Based on the correlation coefficient matrix of the variables, the explanatory variables adopted in this research have significant correlation coefficients to the dependent variables, and the correlation coefficients of explanatory variables to control variables are mostly smaller than 0.3 . Therefore, there is less correlation between explanatory variables and control variables, thus avoiding the multicollinearity of the model in this paper.

Based on the variables above, we carried out the regression analysis on the dependent variable of sales volume with SYS-GMM and panel data fixed effect regression in this paper. To compare the different effects of responses to different types of reviews (negative or positive) on performance, we normalized the variables of the rates of responses to negative and positive reviews and compared the size of the regression coefficients by the Wald test. The specific regression results are given in Table 3.

From the regression results of Table 3 , the rate of response to negative reviews and the rate of response to positive reviews both have a prominent positive effect on sales performance, and the response to reviews has a positive effect on performance overall. The regression coefficient of responses to negative reviews is higher than that of responses to positive reviews, which has been checked by the Wald test. Negative reviews signal more potential customers' concerns on product quality and service, and they are more likely to produce adverse social network effects. The responses to these negative reviews show the seller's social network attitude and capacity to handle a problem timely. It means that the seller can better explain the doubts from the participants in the social network relation, which promotes social network embeddedness and improves the promotion effect of social network on sale performance. Therefore, $\mathrm{H} 1$ and $\mathrm{H} 2$ were verified by the regression results.

We add the interaction item of explanatory variable and moderating variables into the model to verify the moderating effect of the product price and diversity and give the specific results in Table 4 . From the regression results, product price and heterogeneity, as well as the interaction items, all have significant positive regression coefficients. Correspondingly, product diversity promotes sale personalization and product diversification so that consumers need diversified networked sources of information to make buying decisions. Therefore, H3 and H4 were verified.

As for the potential endogenous problem, we conduct several robustness tests. The improvement in sales performance may have an impact on response to online reviews. For example, 
TABLE 3: Regression results of the main effect.

\begin{tabular}{|c|c|c|c|c|}
\hline & \multicolumn{2}{|c|}{ SYS-GMM model } & \multicolumn{2}{|c|}{ Fixed effect of panel data } \\
\hline & Model 1 & Model 2 & Model 3 & Model 4 \\
\hline Positive review rate & $0.157^{* * *}(0.012)$ & $0.157^{* * *}(0.012)$ & $0.156^{* * *}(0.012)$ & $0.154^{* * *}(0.013)$ \\
\hline Number of reviews & $0.176^{* * *}(0.006)$ & $0.171^{* * *}(0.006)$ & $0.175^{* * *}(0.006)$ & $0.170^{* * *}(0.006)$ \\
\hline Trading volume in history & $0.299^{* * *}(0.007)$ & $0.311^{* * *}(0.007)$ & $0.301^{* * *}(0.007)$ & $0.310^{* * *}(0.007)$ \\
\hline Operation months & $0.003(0.003)$ & $0.004(0.003)$ & $0.003(0.003)$ & $0.003(0.003)$ \\
\hline Product price & $0.128^{* * *}(0.045)$ & $1.175^{* * *}(0.209)$ & $0.101^{* * *}(0.043)$ & $0.143^{* * *}(0.051)$ \\
\hline Product heterogeneity & $1.131^{* * *}(0.204)$ & $1.142^{* * *}(0.177)$ & $1.231^{* * *}(0.201)$ & $1.732^{* * *}(0.304)$ \\
\hline Ratio of response to negative review & & $0.798^{* * *}(0.102)$ & & $0.819^{* * *}(0.229)$ \\
\hline Ratio of response to positive review & & $0.239^{* * *}(0.075)$ & & $0.197^{* * *}(0.043)$ \\
\hline Wald test value ( $p$ value) & & $4.56(0.000)$ & & $4.77(0.000)$ \\
\hline Region dummy variable & Included & Included & Included & Included \\
\hline Season dummy variable & Included & Included & Included & Included \\
\hline Industry dummy variable & Included & Included & Included & Included \\
\hline Wald chi ${ }^{2}$ & $242.52^{* * *}$ & $248.09^{* * *}$ & & \\
\hline Sargan test ( $p$ value) & $21.230(0.730)$ & $17.723(0.854)$ & & \\
\hline $\operatorname{AR}^{2}(p$ value $)$ & $0.710(0.478)$ & $0.181(0.856)$ & & \\
\hline$R^{2}$ & & & 0.222 & 0.206 \\
\hline$F$ value & & & 229.12 & 114.11 \\
\hline Number of observed values & 25798 & 25798 & 25798 & 25798 \\
\hline
\end{tabular}

Note. The dependent variable is the sales volume. “***” in the table means that $\mathrm{z}$-statistics are significant at the level of $1 \%$.

TABLE 4: Regression results of moderating effect.

\begin{tabular}{|c|c|c|c|c|c|c|}
\hline & \multicolumn{3}{|c|}{ SYS-GMM model } & \multicolumn{3}{|c|}{ Fixed effect of panel data } \\
\hline & Model 1 & Model 2 & Model 3 & Model 4 & Model 5 & Model 6 \\
\hline $\begin{array}{l}\text { Ratio of response to negative } \\
\text { review }\end{array}$ & $0.705^{* * *}(0.174)$ & $0.778^{* * *}(0.112)$ & $0.611^{* *}(0.298)$ & $0.412^{* * *}(0.177)$ & $0.709^{* * *}(0.177)$ & $\begin{array}{c}0.387^{* * *} \\
(0.098)\end{array}$ \\
\hline $\begin{array}{l}\text { Ratio of response to positive } \\
\text { review }\end{array}$ & $0.201^{* * *}(0.098)$ & $0.210^{* * *}(0.086)$ & $0.107^{*}(0.060)$ & $0.075^{*}(0.040)$ & $0.165^{* * *}(0.030)$ & $\begin{array}{c}0.071^{* * *} \\
(0.015)\end{array}$ \\
\hline Wald test value ( $p$ value) & $4.37(0.000)$ & $4.43(0.000)$ & $4.77(0.000)$ & $3.77(0.000)$ & $4.51(0.000)$ & $3.98(0.000)$ \\
\hline $\begin{array}{l}\text { Ratio of response to negative } \\
\text { review } \\
\times \text { product price }\end{array}$ & $0.105^{* * *}(0.016)$ & & $0.098^{* * *}(0.020)$ & $0.179^{* * *}(0.044)$ & & $\begin{array}{c}0.156^{* * *} \\
(0.043)\end{array}$ \\
\hline $\begin{array}{l}\text { Ratio of response to positive review } \\
\times \text { product price }\end{array}$ & $0.078^{* * *}(0.006)$ & & $0.056^{* * *}(0.010)$ & $0.075^{* * *}(0.020)$ & & $\begin{array}{c}0.069^{* * *} \\
(0.018)\end{array}$ \\
\hline $\begin{array}{l}\text { Ratio of response to negative } \\
\text { review } \\
\times \text { product heterogeneity }\end{array}$ & & $0.096^{* * *}(0.013)$ & $0.076^{* * *}(0.019)$ & & $0.099^{* * *}(0.014)$ & $\begin{array}{c}0.086^{* * *} \\
(0.020)\end{array}$ \\
\hline $\begin{array}{l}\text { Ratio of response to positive } \\
\text { review } \times \text { product heterogeneity }\end{array}$ & & $0.073^{* * *}(0.011)$ & $0.018^{* * *}(0.006)$ & & $0.045^{* * *}(0.010)$ & $\begin{array}{c}0.033^{* * *} \\
(0.011)\end{array}$ \\
\hline Other control variables & Included & Included & Included & Included & Included & Included \\
\hline Wald $\mathrm{chi}^{2}$ & $250.69^{* * *}$ & $205.25^{* * *}$ & $208.42^{* * *}$ & & & \\
\hline Sargan test ( $p$ value) & $23.805(0.587)$ & $14.396(0.952)$ & $14.614(0.950)$ & & & \\
\hline $\operatorname{AR}^{2}(p$ value $)$ & $0.509(0.611)$ & $-0.130(0.896)$ & $-0.188(0.851)$ & & & \\
\hline$R^{2}$ & & & & 0.243 & 0.265 & 0.239 \\
\hline$F$ value & & & & 136.17 & 121.36 & 62.01 \\
\hline Number of observed values & 25798 & 25798 & 25798 & 25798 & 25798 & 25798 \\
\hline
\end{tabular}

Note. The dependent variable is the sales volume. “*," “**," and “****” in the table mean that $\mathrm{z}$-statistics are significant at the levels of $10 \%, 5 \%$, and $1 \%$.

as sales performance improves, sellers get more income, thereby hiring more professional and technical personnel or outsourcing response strategies to other companies. It led to the emergence of fake reviews, which increased the number and quality of responses. In order to eliminate potential endogenous problems, this article adjusts the observed values and uses the sales volume of the next period as the dependent variable. The original explanatory variables, adjusted variables, and controlled variables remain unchanged, and the number of observed values is adjusted accordingly.

Sales may be affected by individual effects like characteristics of the team members, such as the education level and sales experience. These factors are more likely to remain the same during the observation period, so these factors can be viewed as individual effects that do not change over time. We also use a fixed-effects regression model to control 
TABLE 5: Results of robustness test (sales volume of next month as DV).

\begin{tabular}{|c|c|c|c|c|}
\hline & \multicolumn{2}{|c|}{ SYS-GMM model } & \multicolumn{2}{|c|}{ Fixed effect of panel data } \\
\hline & Model 1 & Model 2 & Model 3 & Model 4 \\
\hline Ratio of response to negative review & $0.519^{* * *}(0.172)$ & $0.419^{* *}(0.068)$ & $0.434^{* * *}(0.077)$ & $0.305^{* * *}(0.058)$ \\
\hline Ratio of response to positive review & $0.110^{* * *}(0.036)$ & $0.097^{* * *}(0.020)$ & $0.087^{* * *}(0.022)$ & $0.050^{* * *}(0.009)$ \\
\hline Wald test value ( $p$ value) & $4.40(0.000)$ & $4.15(0.000)$ & $3.98(0.000)$ & $3.60(0.000)$ \\
\hline Ratio of response to negative review $\times$ product price & & $0.064^{* * *}(0.020)$ & & $0.047^{* *}(0.022)$ \\
\hline Ratio of response to positive review $\times$ product price & & $0.265^{* * *}(0.086)$ & & $0.210^{* * *}(0.036)$ \\
\hline Ratio of response to negative review $\times$ product heterogeneity & & $0.077^{* * *}(0.019)$ & & $0.125^{* * *}(0.049)$ \\
\hline Ratio of response to positive review $\times$ product heterogeneity & & $0.105^{* * *}(0.047)$ & & $0.129^{* * *}(0.015)$ \\
\hline Other control variable & Included & Included & Included & Included \\
\hline Wald chi $^{2}$ & $5,025.76^{* * *}$ & $8,646.88^{* * *}$ & & \\
\hline Sargan test ( $p$ value) & $27.503(0.916)$ & $26.386(0.939)$ & & \\
\hline $\mathrm{AR}^{2}$ ( $p$ value $)$ & $1.228(0.219)$ & $1.311(0.190)$ & & \\
\hline$R^{2}$ & & & 0.227 & 0.251 \\
\hline$F$ value & & & 215.91 & 186.10 \\
\hline Number of observed values & 17800 & 17800 & 17800 & 17800 \\
\hline
\end{tabular}

Note. The dependent variable is the sales volume of next month. “**” and “***” in the table mean that $\mathrm{z}$-statistics are significant at the levels of $5 \%$ and $1 \%$.

TABle 6: Results of robustness test (subsample from July 2018 to November 2018).

\begin{tabular}{|c|c|c|c|c|}
\hline & \multicolumn{2}{|c|}{ SYS-GMM model } & \multicolumn{2}{|c|}{ Fixed effect of panel data } \\
\hline & Model 1 & Model 2 & Model 3 & Model 4 \\
\hline Ratio of response to negative review & $0.509^{* * *}(0.115)$ & $0.596^{* *}(0.097)$ & $0.396^{* * *}(0.088)$ & $0.259^{* * *}(0.086)$ \\
\hline Ratio of response to positive review & $0.128^{* * *}(0.030)$ & $0.094^{* * *}(0.011)$ & $0.109^{* * *}(0.034)$ & $0.083^{* * *}(0.011)$ \\
\hline Wald test value ( $p$ value) & $3.93(0.000)$ & $3.51(0.000)$ & $2.98(0.000)$ & $3.27(0.000)$ \\
\hline Ratio of response to negative review $\times$ product price & & $0.069^{* * *}(0.018)$ & & $0.055^{* *}(0.019)$ \\
\hline Ratio of response to positive review $\times$ product price & & $0.277^{* * *}(0.089)$ & & $0.210^{* * *}(0.036)$ \\
\hline Ratio of response to negative review $\times$ product heterogeneity & & $0.089^{* * *}(0.014)$ & & $0.149^{* * *}(0.048)$ \\
\hline Ratio of response to positive review $\times$ product heterogeneity & & $0.137^{* * *}(0.055)$ & & $0.153^{* * *}(0.022)$ \\
\hline Other control variable & Included & Included & Included & Included \\
\hline Wald chi $^{2}$ & $996.73^{* * *}$ & $2,115.69^{* * *}$ & & \\
\hline Sargan test ( $p$ value) & $15.771(1.101)$ & $19.932(1.175)$ & & \\
\hline $\operatorname{AR}^{2}(p$ value $)$ & $0.939(0.195)$ & $1.101(0.139)$ & & \\
\hline$R^{2}$ & & & 0.202 & 0.227 \\
\hline$F$ value & & & 89.93 & 110.72 \\
\hline Number of observed values & 13951 & 13951 & 13951 & 13951 \\
\hline
\end{tabular}

Note. The dependent variable is the sales volume. “**” and “***” in the table mean that $\mathrm{z}$-statistics are significant at the levels of $5 \%$ and $1 \%$.

individual effects, thereby avoiding the potential problem of missing variables. The specific results are shown in Table 5.

Furthermore, we use a subsample to test for robustness. We conduct another regression analysis based on the dataset from July 2018 to November 2018 with the sale per month as the dependent variable $(N=13951)$. Results remain the same and prove all hypotheses, so the model of this study can be seen as robust. The specific results are shown in Table 6.

\section{Conclusion and Implications}

4.1. Conclusion. Sellers' response to online customer reviews at a higher rate can improve sales performance considerably. Such behavior shows the sellers" determination and capability to take social network actions and offers the following advantages: (1) improving their network embeddedness; (2) winning more trust in sellers' products from customers; and (3) increasing their social capital reserves and enabling to obtain more resources from the network. Such responses, including ones to negative reviews, can improve the sales performance significantly. Notably, negative reviews attract more potential customers' concerns. Timely and effective responses to the problems exposed in negative reviews undoubtedly can get better social network effects than those in positive reviews, which are more helpful to improve the network embeddedness.

After a seller gets over an image crisis due to negative reviews in a correct manner, it wins more trust from customers. It increases its social capital reserve, which is useful to improve its sales performance. Product price and heterogeneity take the positive regulating effect in the relation between response and performance; they indicate the seller's social network centrality and business scale; customer tends to hold higher expectations on the seller with higher network centrality and scale. When such expectation is met, customers will have more trust in the seller, and this makes the seller have higher social embeddedness and increase sales.

4.2. Theoretical Insights. We apply social network theory in online contexts, analyze the effect of seller response to buyer's reviews on E-commerce sales performance, and 
provide new analytical tools and perspectives on the topic. Our study strengthens the interpretation power of the theory and broadens the research scope. Second, we discover two heterogeneous variables which may explain the sales variance and discuss the regulating effect of these two factors and add new elements to the existing empirical research framework.

Social networks play an essential role in the development of companies, and existing research studies have already reached a consensus of it. However, existing studies have not paid much attention to two issues. First, where are the boundaries of the size of social networks? A person could not manage a network with more than 150 people, as original studies have shown. Although we do not know the limit of a team's network managing ability, obviously it is not infinite because both cognition and material resources are not infinite. Second, regardless of the importance of social networks, how to build an effective social network? We believe understanding the process of establishing an online social network is more urgent and practical. We see some fascinating insight into the questions above. When sellers respond to customer reviews, the number of social connections and the size of network increase. But limited by its resource (including cognition and material resources), the size would reach a point where it could no longer increase. Therefore, we believe, although we have not tested it yet, that there must be an inverted U-relationship between network size and performance. Our research also suggests that with a higher price and product heterogeneity, networking behavior becomes more efficient. This is interesting because it means when the size of the network reaches its limit, maybe it is a signal to remake pricing strategies and product diversification strategies. After the strategic transformation, the networking process moves into a higher new stage, where the size of the network could increase again, and the effectiveness of the network is enhanced.

4.3. Implication. E-commerce sellers should pay more attention to the response to online reviews and make scientific response strategies based on the characteristics of social network structure. They should reply to as many buyers as possible and increase the degree of embeddedness in the social network. They should also pay special attention to negative reviews, take targeted measures to solve problems, restore buyer's trust, and dispel potential buyers' doubts. When responding to negative reviews, sellers should put more focus on individuals with a high degree of network centrality and pay more attention and invest more resources on them. Responding to as many buyers as possible does not mean responding to all buyers. Sellers should apply a way of social network structure thinking mode and carry out differentiated and targeted responses. The emergence of online communities reflects the development of online social networks for buyers. According to their product diversity and product pricing, sellers should develop differentiated response strategies. They should put more focus on the reviews and responses when the product is expensive and the product diversity is high. They should also build portraits of these buyers and make more specialized strategies.

At the same time, the network connections between sellers are becoming closer, which brings new challenges for sellers to formulate competitive strategies. In the response process, sellers should not only focus on their impact on buyers and potential buyers but also its impact on competitors and potential competitors. Besides, sellers should clarify the "negative fake review" from competitors promptly, severely, and rationally and report the situation to the E-commerce platform supervisor to protect their legitimate rights and their online reputation. Sellers should realize the importance of supply chain social networks. Buyers' reviews are related not only to sellers but also to all upstream producers. After responding to the reviews appropriately, sellers should bring the review information feedback timely to upstream producers and other stakeholders and establish a supply chain network mechanism for problem resolution, demand information sharing, and crisis management.

E-commerce producers should pay more attention to the buyer's demand information feedback sent back by sellers and improve the production process and the product quality to better meet the demand. When facing sellers' feedback, producers should improve their service attitude, make a careful analysis of the questions raised by sellers, offer technical support and staff training support to sellers, and establish longterm cooperative relationships with the seller to ensure longterm smoothness of their own product channels. Besides, producers should take full advantage of the big data from E-commerce transactions, manage the supply chain in a more scientific and precise way, and improve the efficiency and quality of the supply chain.

E-commerce platforms should improve the buyer's review and seller's response functions, reduce the operation difficulty and time cost of both parties, and improve the user experience of both parties. They should make new measures of reviews' effectiveness to help potential buyers get useful reviews faster, thereby improving the user experience and increasing the buyer's willingness to comment on products. They should establish a point system to encourage and promote sellers to actively and proactively respond to relevant buyer reviews. They should take specific economic incentives and provide buyers with lotteries and other methods to encourage them to participate in online reviews actively. They should reexamine the usefulness of buyer reviews, establish a key opinion leader (KOL) mechanism, and improve the platform's reputation system. In addition, they should develop online community systems and gradually increase the connection among producers, sellers, and buyers.

\section{Data Availability}

The data used to support the findings of this study are included within the article. 


\section{Conflicts of Interest}

The authors declare that they have no conflicts of interest.

\section{References}

[1] X. Li and L. M. Hitt, "Self-selection and information role of online product reviews," Information Systems Research, vol. 19, no. 4, pp. 456-474, 2008.

[2] I. Blal and M. C. Sturman, "The differential effects of the quality and quantity of online reviews on hotel room sales," Cornell Hospitality Quarterly, vol. 55, no. 4, pp. 365-375, 2014.

[3] F. Zhu and X. Zhang, "Impact of online consumer reviews on sales: the moderating role of product and consumer characteristics," Journal of Marketing, vol. 74, no. 2, pp. 133-148, 2010.

[4] D. Zhang, L. Zhou, J. L. Kehoe, and I. Y. Kilic, "What online reviewer behaviors really matter? Effects of verbal and nonverbal behaviors on detection of fake online reviews," Journal of Management Information Systems, vol. 33, no. 2, pp. 456481, 2016.

[5] C.-H. Wu, Z. Yan, S.-B. Tsai, W. Wang, B. Cao, and X. Li, “An empirical study on sales performance effect and pricing strategy for E-commerce: from the perspective of mobile information," Mobile Information Systems, vol. 2020, no. 1, pp. 1-8, Article ID 7561807, 2020.

[6] J.-W. Hong and S.-B. Park, "The identification of marketing performance using text mining of airline review data," Mobile Information Systems, vol. 2019, no. 1, pp. 1-8, Article ID 1790429, 2019.

[7] S. Bi, Z. Liu, and K. Usman, "The influence of online information on investing decisions of reward-based crowdfunding," Journal of Business Research, vol. 71, no. 6, pp. 10-18, 2017.

[8] M. Rose and J. G. Blodgett, Are Management Responses to Negative Online Consumer Reviews Beneficial, pp. 102-110, Springer International Publishing, Berlin, Germany, 2016.

[9] H. Crijns, V. Cauberghe, L. Hudders, and A.-S. Claeys, "How to deal with online consumer comments during a crisis? The impact of personalized organizational responses on organizational reputation," Computers in Human Behavior, vol. 75, no. 10, pp. 619-631, 2017.

[10] H. Min, Y. Lim, and V. P. Magnini, "Factors affecting customer satisfaction in responses to negative online hotel reviews," Cornell Hospitality Quarterly, vol. 56, no. 2, pp. 223-231, 2015.

[11] Y. L. Lee and S. Song, "An empirical investigation of electronic word-of-mouth: informational motive and corporate response strategy," Computers in Human Behavior, vol. 26, no. 5, pp. 1073-1080, 2010.

[12] J. A. Barnes, "Class and committees in a Norwegian Island parish," Human Relations, vol. 7, no. 1, pp. 39-58, 1954.

[13] J. C. Mitchell, Social Networks in Urban Situations: Analyses of Personal Relationships in Central African Towns, pp. 59-89, Manchester University Press, Manchester, UK, 1969.

[14] B. Wellman and S. D. Berkowitz, "Social structures: a network approach," American Political Science Association, vol. 83, no. 83 , pp. 102-113, 1988.

[15] M. S. Granovetter, The Strength of Weak Ties, pp. 347-367, The University of Chicago Press, Chicago, IL, USA, 1977.

[16] M. Granovetter, "Economic action and social structure: the problem of embeddedness," American Journal of Sociology, vol. 91, no. 3, pp. 481-510, 1985.
[17] R. S. Burt, Structural Holes: The Social Structure of Competition, Harvard University Press, Cambridge, MA, USA, 1992.

[18] P. Bourdieu, "Economic capital, cultural capital, social capital," Soziale-Welt, Supplement, vol. 2, no. 13, pp. 183-198, 1983.

[19] J. S. Coleman, Foundation of Social Theory, pp. 115-117, The Belknap Press of Harvard University Press, Cambridge, MA, USA, 1990.

[20] G. Drexler and B. Janse, "Social network analysis: an important tool for innovation management," in Evolution of Innovation Management, pp. 59-71, Palgrave Macmillan, London, UK, 2013.

[21] Y. H. Liou, A. J. Daly, and C. Brown, "Foregrounding the role of relationships in reform: a social network perspective on leadership and change," International Journal of Educational Management, vol. 29, no. 7, pp. 67-82, 2015.

[22] S. Soltis, D. Brass, and D. Lepak, "Social resource management: integrating social network theory and human resource management," Academy of Management Annals, vol. 12, no. 2, pp. 537-573, 2018.

[23] B. Fan, L. Liu, and M. Li, "Knowledge recommendation based on social network theory," in Proceedings of the 2008 IEEE Symposium on Advanced Management of Information for Globalized Enterprises (AMIGE), IEEE, Tianjin, China, September 2008.

[24] C. Zhang, Y. Xu, and C. Zhang, "How do people seek knowledge in information system projects: a new perspective from social network theory," in Proceedings of the International Multi-Conference on Computing in the Global Information Technology, IEEE, Athens, Greece, August 2008.

[25] T. Jiang and D. He, "Redefining social network services: a solution to personal information and knowledge management," in Proceedings of the IEEE/WIC/ACM International Conferences on ACM, Fremont, CA, USA, November 2007.

[26] K. S. K. Chung and L. Crawford, "The role of social networks theory and methodology for project stakeholder management," Procedia-Social and Behavioral Sciences, vol. 226, no. 2, pp. 372-380, 2016.

[27] M. Bampo, M. T. Ewing, D. R. Mather, D. Stewart, and M. Wallace, "The effects of the social structure of digital networks on viral marketing performance," Information Systems Research, vol. 19, no. 3, pp. 273-290, 2008.

[28] G. Liu, Z. Wang, and X. Cheng, "“Friend network” advantage, in-group features, and internet entrepreneurship-based on a new integrated view of social identity and embeddedness theory," China Industrial Economics, vol. 1, no. 8, pp. 110-126, 2016.

[29] G. Liu and Z. Wang, "Cultural diversity of entrepreneurial team, and internet entrepreneurial financing-empirical research based on products crowd-funding data," Finance \& Trade Economics, vol. 37, no. 6, pp. 113-128, 2016.

[30] P. Moran, "Structural vs. relational embeddedness: social capital and managerial performance," Strategic Management Journal, vol. 26, no. 12, pp. 1129-1151, 2005.

[31] X. Xu, "Examining an asymmetric effect between online customer reviews emphasis and overall satisfaction determinants," Journal of Business Research, vol. 106, pp. 196-210, 2020.

[32] C. Dhanaraj, M. A. Lyles, H. K. Steensma, and L. Tihanyi, "Managing tacit and explicit knowledge transfer in IJVs: the role of relational embeddedness and the impact on performance," Journal of International Business Studies, vol. 35, no. 5, pp. 428-442, 2004.

[33] D. Bowman and D. Narayandas, "Managing customer-initiated contacts with manufacturers: the impact on share of 
category requirements and word-of-mouth behavior," Journal of Marketing Research, vol. 38, no. 3, pp. 281-297, 2001.

[34] I. Lobel and E. Sadler, "Preferences, homophily, and social learning," Operations Research, vol. 64, no. 3, pp. 564-584, 2016.

[35] L. Qiu, J. Pang, and K. H. Lim, "Effects of conflicting aggregated rating on eWOM review credibility and diagnosticity: the moderating role of review valence," Decision Support Systems, vol. 54, no. 1, pp. 631-643, 2012.

[36] T. Hennig-Thurau, E. C. Malthouse, C. Friege et al., "The impact of new media on customer relationships," Journal of Service Research, vol. 13, no. 3, pp. 311-330, 2010.

[37] J. A. Chevalier and D. Mayzlin, "The effect of word of mouth on sales: online book reviews," Journal of Marketing Research, vol. 43, no. 3, pp. 345-354, 2006.

[38] S. Gupta and H.-W. Kim, "Value-driven Internet shopping: the mental accounting theory perspective," Psychology \& Marketing, vol. 27, no. 1, pp. 13-35, 2010.

[39] C.-M. Chiu, E. T. G. Wang, Y.-H. Fang, and H.-Y. Huang, "Understanding customers' repeat purchase intentions in B2C e-commerce: the roles of utilitarian value, hedonic value and perceived risk," Information Systems Journal, vol. 24, no. 1, pp. 85-114, 2014.

[40] J. Ren, D. M. Zhao, and X. H. Zhang, "Online buying decision preference and prospect theory," Advanced Materials Research, vol. 12, no. 5, pp. 926-930, 2014.

[41] J.-S. Chiou and C. Cheng, "Should a company have message boards on its Web sites?" Journal of Interactive Marketing, vol. 17, no. 3, pp. 50-61, 2003.

[42] N. N. Ho-Dac, S. J. Carson, and W. L. Moore, "The effects of positive and negative online customer reviews: do brand strength and category maturity matter?" Journal of Marketing, vol. 77, no. 6, pp. 37-53, 2013.

[43] J. Berger, A. T. Sorensen, and S. J. Rasmussen, "Positive effects of negative publicity: when negative reviews increase sales," Marketing Science, vol. 29, no. 5, pp. 815-827, 2010.

[44] L. Harris and A. Rae, "Social networks: the future of marketing for small business," Journal of Business Strategy, vol. 30, no. 5, pp. 24-31, 2009.

[45] L. J. Spence and R. Schmidpeter, "SMEs, social capital and the common good," Journal of Business Ethics, vol. 45, no. 1-2, pp. 93-108, 2003.

[46] K. V. Lins, H. Servaes, and A. Tamayo, "Social capital, trust, and firm performance: the value of corporate social responsibility during the financial crisis," The Journal of Finance, vol. 72, no. 4, pp. 1785-1824, 2017.

[47] H. Robert, Handbook of Risk and Crisis Communication, pp. 120-135, Routledge, Abingdon, UK, 2010.

[48] Z. Deng and Z. Wang, "Early-mover advantages at crossborder business-to-business e-commerce portals," Journal of Business Research, vol. 69, no. 12, pp. 6002-6011, 2016.

[49] O. Hinz, I. H. Hann, and M. Spann, "Price discrimination in E-commerce? An examination of dynamic pricing in nameyour-own price markets," Mis Quarterly, vol. 15, no. 4, pp. 81-98, 2011.

[50] E. Maslowska, E. C. Malthouse, and V. Viswanathan, "Do customer reviews drive purchase decisions? The moderating roles of review exposure and price," Decision Support Systems, vol. 98, pp. 1-9, 2017.

[51] S. M. Mudambi and D. Schuff, "Research note: what makes a helpful online review? A study of customer reviews on Amazon.com," MIS Quarterly, vol. 34, no. 1, pp. 185-200, 2010.

[52] M. O. Jackson, Social and Economic Networks, Princeton University Press, Princeton, NJ, USA, 2010.
[53] P. G. Patterson, "Expectations and product performance as determinants of satisfaction for a high-involvement purchase," Psychology and Marketing, vol. 10, no. 5, pp. 449-465, 1993.

[54] B. Gu, J. Park, and P. Konana, "Research note-the impact of external word-of-mouth sources on retailer sales of highinvolvement products," Information Systems Research, vol. 23, no. 1, pp. 182-196, 2012.

[55] G. Ahuja, F. Polidoro, and W. Mitchell, "Structural homophily or social asymmetry? The formation of alliances by poorly embedded firms," Strategic Management Journal, vol. 30, no. 9, pp. 941-958, 2009.

[56] G. Walker, B. Kogut, and W. Shan, "Social capital, structural holes and the formation of an industry network," Organization Science, vol. 8, no. 2, pp. 109-125, 1997.

[57] J. Tan, H. Zhang, and L. Wang, "Network closure or structural hole? The conditioning effects of network-level social capital on innovation performance," Entrepreneurship Theory and Practice, vol. 39, no. 5, pp. 1189-1212, 2015.

[58] L. Rhee and P. M. Leonardi, "Which pathway to good ideas? An attention-based view of innovation in social networks," Strategic Management Journal, vol. 39, no. 4, pp. 1188-1215, 2018.

[59] N. Bosma, M. Van Praag, R. Thurik, and G. de Wit, "The value of human and social capital investments for the business performance of startups," Small Business Economics, vol. 23, no. 3, pp. 227-236, 2004.

[60] W. T. Robinson, C. Fornell, and M. Sullivan, "Are market pioneers intrinsically stronger than later entrants?" Strategic Management Journal, vol. 13, no. 8, pp. 609-624, 1992.

[61] G. Khatwani and P. R. Srivastava, "Impact of information technology on information search channel selection for consumers," Journal of Organizational and End User Computing, vol. 30, no. 3, pp. 63-80, 2018.

[62] L. Fabisiak, "Web service usability analysis based on user preferences," Journal of Organizational and End User Computing, vol. 30, no. 4, pp. 1-13, 2018.

[63] A. Shahri, M. Hosseini, K. Phalp, J. Taylor, and R. Ali, "How to engineer gamification," Journal of Organizational and End User Computing, vol. 31, no. 1, pp. 39-60, 2019.

[64] T. Grubljesic, P. S. Coelho, and J. Jaklic, "The shift to socioorganizational drivers of business intelligence and analytics acceptance," Journal of Organizational and End User Computing, vol. 31, no. 2, pp. 37-64, 2019.

[65] S. Namasudra and P. Roy, "PpBAC," Journal of Organizational and End User Computing, vol. 30, no. 4, pp. 14-31, 2018. 